\title{
IM, Not IP (Information Pollution)
}

$\mathbf{R}$ espected technology commentators say that they now prefer instant messaging (IM) over e-mail as their medium of choice for computer-mediated communication. ${ }^{1}$ The main reasons are that e-mail has become an overloaded channel for readers and that you can't be sure to get a timely response from the recipients of your e-mail.

Yes, e-mail is suffering. Indeed, it's very close to the breaking point where it will stop being useful, whether for personal communication or for company newsletters. Here are some representative user comments from a recent study of e-mail newsletters: ${ }^{2}$

- "I used to be on more lists, but not now. When I was newer to the Web, I signed up for a lot of stuff. But then I realized I couldn't keep up. It was more work to delete them than any benefit I was getting reading them."

- "It's the sort of thing I don't have time for. It would be good when I retire. Then it's something I could look at daily. I'd be embarrassed to read it at work, but I don't want to read e-mail on the weekends."

- "I hate junk mail. My friend on Hotmail gets a lot more. I take it as a personal assault, though I shouldn't."

- "Once you get on, it seems like you can never really erase yourself."

When a long-term employee who used to shoulder a heavy workload and be one of your most valued contributors becomes sick, what do you do? Shoot the poor fellow? Usually, the better answer is to see if there's a cure.

I think we need to cure e-mail, not kill it. But it will surely die if left unattended.

It is naive to believe that IM is the answer to the information overload that's ailing e-mail. Continue current trends a few years and most people will get so much IM that they will have to tune it out to get any work done.

IM is even worse than e-mail with respect to one of the most important human-factors criteria: It's interruptive of task flow because it demands realtime attention. Some things do need realtime attention, but even a one-minute interruption can easily cost a knowledge

\author{
A steady dose of \\ REALTIME INTERRUPTIONS \\ IS TOXIC TO ANYONE'S \\ HEALTH.
}

worker 10 to 15 minutes of lost productivity due to the time needed to reestablish mental context

and reenter the flow state. That's why one of the best ways of increasing the productivity of programmers is to give them individual offices. And that's why no e-mail program should come with the biff feature turned on by default. (Biff is the annoying ability to ring a bell or flash the screen every time an e-mail message arrives. In fact, the world economy would gain several million dollars per year if this feature were completely eradicated.)

Our culture is hurting from information pollution everywhere we turn. The Internet is the most severely afflicted ecosystem, with countless content-free Web pages overflowing with either low-value stream-ofconsciousness postings or bland "corporatese." The physical world is not much better. In the United States, for example, you can't buy a lawn mower without a label saying that you're not supposed to mow your feet. Most instruction manuals are littered with "important" warnings that caution against obvious stupidities, burying actual dangers amid a mass of irrelevancy.

IM is one more toxic spill that's directing our attention to short-term minor issues at the cost of procrastinating on important tasks that require more than a few minutes of uninterrupted thinking. Any time-management consultant will tell you that the basics of meeting your goals are to prioritize them and spend the most time on the most important problems. To make real progress in creative thinking, problem solving, or other knowledge work, we need to keep out interruptions and set our own agenda. IM, in contrast, lets your agenda be controlled by anybody who has your screen name.

Remember that a one-minute interruption costs you ten minutes of productivity. Only very important instant messages are worth 1,000 percent in overhead costs.

The Web is a junkyard. E-mail is suffocating users. IM destroys productivity. What can we do about this?

I have my own suggested solution, which I call the Internet control panel. This would be a single central base for monitoring and prioritizing all the information a user 
is interested in. Do you want to keep track of your eBay auctions? Instead of five e-mails per auction, all scattered throughout your inbox, you would have a single flag in the control panel. Discussion groups? The control panel would show when hot topics of interest to you are being discussed and would call attention to discussions with contributions by writers you particularly respect. E-mail? Restricted to truly personal communication. Newsletters, intranet status reports, and other nonletter communications would be summarized and available for perusal on request. IM would have a small role, but your personal agent would be very strict at screening incoming requests.

Whether or not you believe in my control panel, the most important point is to change our ideology for computer-mediated communication. The old thinking was that more information was better. If a unit of information were sent, it would have to be transmitted and received at all costs. The new thinking must be that human time is our most precious resource. Stop strip-mining it.

Traditional operating systems managed and scheduled computer resources. The next generation of computers must protect users' time just as strictly as the most vigilant executive secretary protects a CEO's calendar. $Q$

\section{REFERENCES}

1. Gillmor, D. Spamming sleazebags ruining e-mail. San Jose Mercury News (August 31, 2003); see http: //www.siliconvalley.com/mld/siliconvalley/business/ columnists/dan_gillmor/6661839.htm.

2. Stover, A., and Nielsen, J. E-mail newsletter usability: 79 design guidelines for subscription, newsletter content and account maintenance based on usability studies. Nielsen Norman Group, Fremont, CA. 2002; see http://www.nngroup.com/reports/newsletters,.

JAKOB NIELSEN is principal of Nielsen Norman Group, a user research company focused on making technology more suited to humans. He was previously a Sun Microsystems distinguished engineer and holds 71 U.S. patents on ways of improving Internet usability. Nielsen's books include Designing Web Usability: The Practice of Simplicity and Homepage Usability: 50 Websites Deconstructed. His Web site is http://www.useit.com.

○2003 ACM 1542-7730/03/1100 \$5.00 